\title{
DIDÁTICA DA HISTÓRIA COMO SUB-DISCIPLINA DA CIÊNCIA HISTÓRICA $^{1}$
}

TEACHING HISTORY AS A SUBDISCIPLINE OF HISTORICAL SCIENCE

Rafael Saddi ${ }^{2}$

RESUMO: Este artigo pretende analisar a relação entre Ciência Histórica e Didática da História. Ele apresenta a opinião, originada na bibliografia alemã dos anos 70 , de que a Didática da História é uma sub-disciplina dos estudos históricos. Esta definição confronta a opinião padrão a respeito do que é a Didática da História, como ela opera, e qual o seu objeto de investigação.

Palavras-Chave: Didática da História. Teoria da História. Ciência histórica.

ABSTRACT: This paper aims to analyze the relationship between historical science and history didactics. It presents the opinion, originated in the German literature of the seventies, that history didactics is a sub-discipline of historical studies. This definition confronts the standard opinion of what history didactics is, how it works, and what is his subject matter.

Keywords: History didactics. Theory of History. Historical Science.

\footnotetext{
${ }^{1}$ N. E. manteve-se a grafia do autor "sub-disciplina" ao invés de "sub-disciplina".

2 Professor Adjunto da UFG (Universidade Federal de Goiás). Doutor em História pela UFG.
} 


\section{Introdução}

Existe uma charge em uma contracapa de um famoso livro de Peter Burke que mostra o rei Luís XIV despido: calvo sem sua peruca, barrigudo sem suas mantas e baixo sem seus saltos altos. Não seria difícil imaginar a reação que teria o rei sol que os franceses conheceram em seus grandiosos rituais públicos, se fosse de repente posto frente a frente com este homem despido. Com ataques de riso ou de raiva, ordenaria aos seus criados que retirassem imediatamente aquele ser horrendo de sua frente. E com a arrogância dos ignorantes, desprezaria o corpo vil e nu, sem saber que era o seu próprio corpo que naquele instante ele negava.

Pode acontecer que, de tanto andarmos vestidos, reluzentes em nossos adereços, e sendo elogiados por todos os que nos cercam, esqueçamos o quão simples e comuns somos quando nos despimos. Assim também parece ser o caso do historiador que ridiculariza as questões de ensino e aprendizagem, tomandoas como baixas e mesquinhas, e ignora que elas compõem o ser da nossa própria profissão, a de produzir histórias.

Este artigo pretende discutir justamente esta relação entre a Ciência da História e a Didática da História. Nosso objetivo é apresentar a noção formulada na historiografia alemã dos anos 70 de que a Didática da História é uma parte inerente da Ciência Histórica.

Defender esta tese significa confrontar a ainda existente separação entre Ciência Histórica e Didática da História expressa na noção de que as questões de ensino e aprendizagem da História são exteriores aos estudos históricos.

Esta separação entre Ciência Histórica e Didática da História é sustentada por uma concepção restrita da Ciência Histórica, por um lado, e por uma concepção não menos estreita da Didática da História, por outro. Como veremos, ocorre uma redução da Ciência Histórica à metodologia da pesquisa e da Didática da História à metodologia de ensino.

Na última década, entretanto, diferentes autores começaram, no Brasil, a questionar esta separação, produzindo tanto uma ampliação da concepção de Ciência Histórica quanto da definição de Didática da História. Inicia-se, no âmbito da Ciência do Aprendizado Histórico, aquilo que Cerri (2010) chamou de mudança de paradigmas. 
As pesquisas sobre a metodologia da Educação Histórica vêm questionando a pedagogização do ensino de História. (SCHMIDT, 2004). Tal expressão não deve ser, como muito bem salientou Urban (2009, p. 170), considerada de forma pejorativa. Ela simplesmente indica que o ensino de História foi "considerado unicamente ou predominantemente com base nas discussões de caráter normativo e técnico, revelando a ausência de uma epistemologia pensada na própria História". (URBAN, 2009, p. 170).

Ao colocar como central a compreensão das ideias históricas dos alunos e professores, a metodologia da Educação Histórica se volta para o acúmulo teórico e epistemológico da Ciência Histórica, visando pensar o ensino de História a partir das elaborações próprias do pensamento histórico. Como afirma Schmidt

Na perspectiva da cognição situada na ciência de referência, a forma pela qual o conhecimento deve ser aprendido pelo aluno deve ter como base a própria racionalidade histórica, e os processos cognitivos devem ser os mesmos da própria epistemologia da ciência da História (SCHMIDT, 2009, p. 210).

Do mesmo modo, alguns artigos teóricos apresentam tentativas instigantes de ampliação da definição da Didática da História. Oldimar Cardoso (2008), por exemplo, percebeu que, na historiografia alemã, a Didática da História (Geschichtsdidaktik) é parte inerente da História e não uma didática geral de uma disciplina. Como afirma:

A didática circunscrita pelo conceito de Geschichtsdidaktik pertence à História, é uma parte indissociável dela. A Geschichtsdidaktik abrange mais do que a realidade escolar, ela estuda a "consciência histórica na sociedade". Essa didática não é apenas mais uma Didaktik der... (didática da...), mas um todo cuja definição numa única palavra - Geschichtsdidaktik - pode não ser casual. (CARDOSO, 2008, p. 158).

Como uma parte indissociável da Ciência da História, a Didática da História, abrange muito mais do que o ensino de história nas escolas. Para ele, a Didática da História é

(...) uma disciplina que tem por objeto de estudo todas as elaborações da História sem forma científica. Essa definição fundamenta-se sobretudo na bibliografia alemã contemporânea sobre a Geschichtsdidaktik, surgida em oposição às definições da Didática como arte de ensinar - Lehrkunst - ou como coleção de 
métodos indiferentemente utilizáveis no ensino de qualquer disciplina escolar -Unterrichtsmethoden. (CARDOSO, 2008, p. 165).

Neste sentido, para Cardoso, a Didática da História é uma parte inerente da História que analisa todas as elaborações da História sem forma científica ${ }^{3}$.

Luís Fernando Cerri, por outro lado, a partir do conceito de Consciência Histórica também tem contribuído para este deslocamento rumo à Ciência Histórica. Em um artigo publicado em 2001, Cerri defende a noção de que a Didática da História é uma disciplina interna à Ciência Histórica: A discussão sobre consciência histórica coloca-nos diante da necessidade de dar continuação à proposição de Klaus Bergmann e de Jörn Rüsen, entre os outros autores, de uma didática da história, que seria uma disciplina interna à ciência da história. (CERRI, 2001, p. 109).

Em artigos posteriores, Cerri tem apresentado-se mais cauteloso em relação a esta definição da Didática da História como inerente aos estudos históricos. Em 2004, defendeu a noção de que, segundo Bergmann, a Didática da História é entendida como um campo inter-disciplinar. Como afirma:

Bergmann define, portanto, a Didática da História como campo interdisciplinar, vinculado à História e à Educação, responsável pela produção do conhecimento necessário à metodologia do ensino e à política educacional para a História informadas e críticas. (CERRI, 2004, s/p.).

Em 2010, ao fazer um balanço desta ampliação do conceito de Didática da História no Brasil, afirma:

A Didática de História vem passando, no Brasil, por uma mudança paradigmática, deslocando-se da metodologia do ensino à área interdisciplinar que, sustentada na Teoria da História, articula

\footnotetext{
3 Temos uma discordância da noção de que a Didática da História investiga as elaborações da História sem forma científica. Embora concordemos que esta posição de Cardoso amplia a concepção de Didática da História, ao ir além do estudo da História escolar, ela também apresenta uma restrição ao deixar de fora do campo de investigação da Didática da História as elaborações científicas da História. Para nós, como pode ser percebido em nosso artigo Didática da História como Meta-Teoria, a Didática da História se debruça também sobre a própria Ciência Histórica, tomando-a como objeto de investigação e analisando os pressupostos didáticos da história metodicamente regulada (Ciência Histórica). (SADDI, 2011). Na Alemanha, o principal autor a desenvolver esta noção de que a Didática da História deve ter a Ciência da História como objeto de investigação foi Klaus Bergmann. Sua percepção pode ser analisada no artigo Zum Verhältins von Geschichtswissenschaft und Geschichtsdidaktik, escrito por Bergmann e Rüsen (1978), bem como nos artigos escritos somente por Bergmann, Geschichtsdidaktik als Sozialwissenschaft (1980) e Geschichte in der didaktischen Reflexion (2008) - este último traduzido para o português como História na reflexão didática (1989).
} 
saberes pedagógicos e sócio-antropológicos para debruçar-se sobre o fenômeno da aprendizagem histórica e da circulação social do conhecimento histórico. (CERRI, 2010, p. 277).

Como se pode perceber, Cerri vê a Didática da História como sendo sustentada na Teoria da História. Ele reivindica, assim, os vínculos entre a Didática da História e as reflexões metateóricas da Ciência Histórica, ao mesmo tempo em que define a Didática da História como uma área interdisciplinar.

Os motivos para esta cautela em definir o caráter disciplinar da Didática da História são justificáveis. Isto porque, como disse Cerri (2003, s/p), a tomada de posição em relação ao caráter disciplinar da área tradicionalmente conhecida por Ensino de História esteve constantemente ligada à "(...) disputa pelo seu lugar institucional nas Universidades".

Mais do que uma questão meramente administrativa ou um embate de interesses por parte de grupos diferentes dentro da academia, a discussão sobre "onde deve ficar a prática de ensino de História" (e outras disciplinas) reflete questões de caráter teórico mais profundo, que poderíamos traduzir por "quem - ou qual disciplina tem legitimidade para pesquisar o ensino de História e formar o seu professor". Na verdade, considerando que a formação do professor é uma soma de múltiplas contribuições, a disputa que se estabelece é pelo comando, pela hegemonia do processo. (CERRI, 2003, s/p).

Ao mesmo tempo, Cerri percebe que, embora o pensamento alemão apresente a Didática da História como uma disciplina da Ciência Histórica, na prática, não há uma disciplina no Brasil, mas uma área de interesse interdisciplinar conhecida por Ensino de História:

Epistemologicamente (seguindo o raciocínio de Bergmann), estamos diante de uma nova disciplina dentro da ciência histórica cujo motor principal é, como já foi argumentado acima, a compreensão, avaliação e melhoramento da circulação do conhecimento histórico pela sociedade e seu uso pelos diferentes grupos, incluso aí o sistema educacional e a educação informal. Ocorre que, na prática, o ensino de História vem se constituindo do trabalho de pesquisadores que estão institucionalmente ligados a História e à Educação, principalmente, valendo-se de conceitos, métodos e técnicas dessas e de outras ciências, e portanto institucionalmente o que existe não é ainda uma disciplina, mas uma área de interesse interdisciplinar que é compartilhada por profissionais diversos, dentro e fora da academia, e isso é de uma riqueza ímpar. (CERRI, $2003, s / p)$. 
Situando-nos no interior deste processo de ampliação da Didática da História, gostaríamos de acrescentar algumas contribuições para pensarmos esta relação entre Ciência Histórica e Didática da História.

Consideramos importante questionar qual é o caráter disciplinar da Didática da História. Concordamos com Cerri que a Didática da História é uma área interdisciplinar. Sua atuação não se encerra na referência à Teoria da História. Longe disto, sua relação com a Psicologia, com a Pedagogia, com as Ciências Sociais e com a Filosofia é bastante evidente. Porém, é preciso tanto refletir sobre este lugar entre-disciplinas, quanto ir além da noção de "área" para pensarmos a Didática da História como uma "disciplina"4. Neste sentido, questionamos: trata-se de uma área interdisciplinar autônoma que lida com as diferentes disciplinas de forma igualitária? Trata-se de uma disciplina da Educação que tem referências com a Teoria da História? Trata-se, ao contrário, de uma disciplina da História que se relaciona com outras ciências afins?

Gostaríamos quanto a esta questão, de resgatar a tese formulada na Alemanha em meados dos anos 70, segundo a qual a Didática da História é uma "sub-disciplina da Ciência Histórica" (Unterdisziplin der Geschichtswissenchaft) ou ainda uma "disciplina-parte da Ciência Histórica (Teildisziplin der Geschichtswissenschaft). Tal definição disciplinar da Didática da História nos parece fundamental, posto que ela é uma consequência daquilo que Jeismann definiu como a função didática básica da História (die didaktische Grundfunktion der Historie). Para nós, a ausência de uma definição clara do caráter disciplinar da Didática da História impede-nos de estabelecermos com êxito a relação que o trabalho didático estabelece com as diferentes disciplinas e, ao mesmo tempo, causa prejuízos para toda a sua área de investigação, inclusive para o próprio ensino escolar da História.

Para realizarmos tal tarefa, analisaremos, primeiramente, o processo de expulsão da Didática da História da Ciência Histórica, processo que foi caracterizado pela redução da Ciência Histórica à metodologia da pesquisa e da Didática da História à metodologia de ensino. Depois, analisaremos a definição

\footnotetext{
${ }^{4}$ A definição da Didática da História como uma disciplina nos parece importante sobretudo do ponto de vista prático. Na nova matriz curricular do curso de licenciatura em História da UFG (Universidade Federal de Goiás), a Didática da História foi inserida como uma disciplina. Ela caminha desta forma para alcançar o status que já possuem as demais disciplinas históricas.
} 
da Didática da História como sub-disciplina da Ciência História, bem como sua relação com as disciplinas afins.

\section{A Expulsão da Didática da História da Ciência Histórica}

Em seu famoso artigo Historia Magistra Vitae, Koselleck (2006, p. 41) cita um relato de Friedrich Von Raumer, historiógrafo do governo da Prússia no século XIX:

Durante uma reunião, Oelsen, chefe de departamento no Ministério das Finanças, defendia vivamente a impressão de grande papel-moeda para pagar dívidas. Uma vez esgotados os argumentos contrários, eu (conhecendo meu homem) disse com demasiada ousadia. "Mas senhor Conselheiro Privado, o senhor certamente se lembra que já Tucídides falava do mal que sucedeu quando, em Atenas, decidiu-se imprimir papel-moeda em grande quantidade". "Essa é uma experiência de grande importância", ele retrucou em tom conciliador, deixando-se assim convencer, para manter a aparência de erudição (KOSELLEK, 2006, p. 41).

Koseleck nos mostra que Von Raumer mentiu sobre a impressão de papelmoeda em Atenas. "Sabia que os antigos jamais conheceram papel-moeda. Usou a mentira porque podia calcular o efeito dela. E esse efeito nada mais é do que a afirmação do velho topos de que a história é a mestra da vida" (KOSELLEK, 2006, p. 41).

Ao contrário da visão predominante ainda hoje, até fins do século XVIII prevaleceu a noção de que a didática ocupava um papel central na formulação de qualquer história. (RÜSEN, 2007a). Ensinava-se e escrevia-se a história "a fim de que seus destinatários aprendessem alguma coisa para a vida". (RÜSEN, 2007a p. 88). Mesmo a noção de um "Método" da história era tido como uma questão didática. A escrita da história era orientada por problemas práticos da vida "e não por problemas teóricos ou empíricos da cognição metódica". (RÜSEN, 2007a p. 88).

Assim parecia ser, segundo Koselleck, desde a antiguidade clássica, quando servia-se da "história como coleção de exemplos" a fim de que fosse possível "instruir por meio dela". (2006, p. 43). 
E ainda quando a história já havia alcançado o seu estatuto científico, o conceito de Didática manteve um enorme prestígio para alguns autores. Droysen, por exemplo, a considerava como "a forma mais elevada da historiografia." Como afirmava:

Do interesse didático exsurge a carência dessa forma histórica universal, na qual somente se justifica a ciência histórica como tal. Pois é somente nessa forma que ela se realiza plenamente, constituindo-se na totalidade que lhe é concedida. (DROYSEN apud RÜSEN, 2007a, p. 88).

Segundo Jeismann, no século XIX, mesmo em Ranke (considerado injustamente defensor de uma história não interpretativa), vigorou a ideia de que a própria escrita da História "trazia junto de cada desenvolvimento da crítica de fontes, suas próprias vontades de demonstração e ação, seu engajamento político imediato em suas representações." (JEISMANN, 1977, p. 21)

Entretanto, uma mudança profunda havia ocorrido entre os dois mil anos em que a História foi entendida como uma mestra da vida, dotada de uma essência didática fundamental, escrita para ensinar os homens do presente e do futuro; e o tempo em que nós vivemos, em que o historiador, vestido em seu glamoroso método científico, se tornou incapaz de perceber os elementos didáticos que compõem a sua própria disciplina.

Koselleck nos mostrou que o antigo topos de Cícero estava amparado em um espaço de experiência específico, cujas premissas eram a constância tanto da natureza humana quanto das premissas com os quais os homens interpretavam o mundo. Como disse:

Até o século XVIII, o emprego de nossa expressão (História Magistra Vitae) permanece como indício inquestionável da constância da natureza humana, cujas histórias são instrumentos recorrentes apropriados para comprovar doutrinas morais, teológicas, jurídicas ou políticas. Mas, da mesma forma, a perpetuação de nosso topos aludia a uma constância efetiva das premissas e pressupostos, fato que tornava possível uma semelhança potencial entre os eventos terrenos. $E$, quando uma transformação social ocorria, era de modo tão lento e em prazo tão longo, que os exemplos do passado continuavam a ser proveitosos.

A estrutura temporal da história passada delimitava um espaço contínuo no qual acontecia toda a experimentação possível. (KOSELLECK, 2006, p. 43). 
Um conjunto de mudanças profundas no século XVIII transformou este espaço de experiência e terminou por esvaziar o sentido do antigo topos. Começava a prevalecer a ideia de que a História não ensina através de exemplos, posto que o que foi certo para um tempo passado, não seria válido para um outro tempo, o tempo presente.

Mas, se no século XVIII ocorreu um processo de esvaziamento do antigo topos, no século XIX, com a cientifização e especialização da história, consolidouse de vez as barreiras que separavam a História da vida prática. Este processo ocorreu somente no final do século XIX. (JEISMANN, 1977).

Segundo Jeismann (1977 p. 21), "se impôs a pretensão prévia" de que a Ciência Histórica era produzida independentemente "das vontades políticas do presente". Tal processo construiu uma noção restrita de Ciência da História, derrubando a Didática do posto que ocupava e expulsando-a da Ciência Histórica. Como afirma Rüsen:

(...) devido a crescente institucionalização e profissionalização da história, a importância da didática da história foi esquecida ou minimizada. Durante o século XIX, quando os historiadores definiram sua disciplina, eles começaram a perder de vista um importante princípio, a saber, que a história é enraizada nas necessidades sociais para orientar a vida dentro da estrutura tempo. (RÜSEN, 2006, p. 08)

Quando a História perdeu esta percepção das suas funções na orientação temporal do agir e do sofrer humanos na vida prática, a Didática perdeu o seu posto para a metodologia da pesquisa histórica.

Como os historiadores do século XIX se esforçaram para tornar a história uma ciência, este público foi esquecido ou redefinido para incluir apenas um pequeno grupo de profissionais especialistas treinados. A didática da história não era mais o centro da reflexão dos historiadores sobre sua própria profissão. Ela foi substituída pela metodologia da pesquisa histórica. A "cientifização" da história acarretou um estreitamento consciente de perspectiva, um limitador dos propósitos e das finalidades da história 2. A esse respeito, a cientifização da história excluiu da competência da reflexão histórica racional aquelas dimensões do pensamento histórico inseparavelmente combinadas com a vida prática. Desse ponto de vista, pode ser dito que a história científica, apesar de seu clamor racionalista, havia conduzido aquilo que eu gostaria de chamar "irracionalização" da história. (RÜSEN, 2006, p. 08). 
Ou seja, a História deixou de responder às necessidades práticas dos homens, perdendo a sua tarefa de ensino e aprendizado, para se dirigir exclusivamente ao grupo de pesquisadores especializados. Ela não legitimava-se mais por suas funções de orientação, mas simplesmente pelo fato de existir.

A Ciência da História reduzia-se à metodologia da pesquisa, de tal forma, que Alfred Heuss no final dos anos 50 podia dizer que a pesquisa histórica obedecia "inteiramente à autonomia dos seus impulsos cognitivos". (JEISMANN, 1977, p. 22). Nesta perspectiva, a História produzida pela pesquisa histórica somente tinha "algo a dizer para si mesma e perdeu a referência (relação) primordial com a realidade da vida". (JEISMANN, 1977, p. 22). Rüsen também exemplificou esta substituição da Didática pela metodologia da pesquisa a partir de uma metáfora utilizada por Heuss, comparando a História a uma árvore. Dizia: "A árvore vive enquanto tem folhas e é seu destino viver e ter folhas." (HEUSS apud RÜSEN, 2006, p. 10).

Esta perda da noção de que a História ensina também produziu uma redução da percepção da Didática da História. Segundo Jeismann, a Didática da História era

(...) uma área ainda não aprovada (legalizada, legitimada, licenciada) cientificamente, que descreve o esforço (esforço) dos homens de escolar para aproximar de um modo elementar os resultados da pesquisa histórica como lições aprendidas (descobertas) sobre o passado (JEISMANN, 1977, p. 09)

Ao menos dois elementos são importantes nesta percepção. Primeiro, o fato de que a Didática da História não era ainda uma disciplina científica. Segundo, que ela reduzia-se à elaboração de métodos para transmissão de um conhecimento que ela mesma não produzia. O historiador produzia o conhecimento, o didático o transmitia.

Tal percepção de Jeismann sobre a visão predominante da Didática da História é semelhante à posição que Rüsen apresentou alguns anos depois, onde afirmava que a opinião padrão sobre a Didática da História a definia como:

(...) uma abordagem formalizada para ensinar histórias em escolas primárias e secundárias que representa uma parte importante da transformação de historiadores em professores de história nestas escolas. É uma disciplina que faz a mediação entre a história como disciplina acadêmica e o aprendizado histórico e a educação escolar. Assim, ela não tem nada a ver com o trabalho dos historiadores em 
sua própria disciplina. A didática da história serve como ferramenta que transporta conhecimento histórico dos recipientes cheios de pesquisa acadêmica para as cabeças vazias dos alunos. (RÜSEN, 2006, p. 08).

Porém, além do fato de não ser uma área legitimada cientificamente, e além de centrar suas análises predominantemente na metodologia do ensino de História, tal percepção da Didática da História a via como uma instância separada da Ciência Histórica 5 .

Desta forma, consolidava-se a divisão entre Ciência Histórica e Didática da História a partir da redução da primeira à metodologia da pesquisa e da segunda à metodologia de ensino. O fim desta separação exigia tanto uma ampliação da concepção de Ciência Histórica quanto de Didática da História. Era preciso que a Ciência Histórica percebesse os seus vínculos com a vida prática humana e que a Didática da História compreendesse a sua relação com o trabalho metódico dos historiadores.

O questionamento sobre a separação entre Didática da História e Ciência Histórica deu-se na Alemanha dos anos 60 e 70 como resposta a uma crise de legitimidade da Ciência Histórica e do Ensino de História.Tal crise significava uma perda de legitimidade social pensamento histórico. (SYWOTTEK, 1974; JEISMANN, 2000). Como afirmava Bergmann (1998), a crise estava ligada ao fato de que nem a Ciência da História nem o Ensino de História estavam em condições de atender às demandas e necessidades que a sociedade alemã apresentava. A História precisava proporcionar à sociedade e aos homens que nela viviam "uma identidade na mudança temporal e uma auto-compreensão orientadora da ação dentro da sociedade", mas estava abaixo destas tarefas. (BERGMANN, 1998, p. 33).

No âmbito da Teoria da História, a reflexão sobre os fatores e fundamentos da Ciência Histórica possibilitou a superação da redução dos estudos históricos à metodologia da pesquisa. Ao retomar as categorias interesses e funções, a Ciência Histórica passou a ser pensada em seu vínculo

\footnotetext{
5 Jeismann (1977, p. 17) combate duas teses que ele considerava bastante reproduzidas na Alemanha a respeito do que era a Didática da História. A primeira afirmava que "a Didática da História é uma concretização disciplinar específica da Didática geral e fundamentada nessa Didática geral ou em uma Teoria do Currículo geral." A segunda, por sua vez dizia que "a Ciência da História tem a ver com a Didática somente indiretamente, quando ela controla o resultado da pesquisa à disposição e a justeza (exatidão) da redução didática". Nestas duas posições, a Didática da História não é compreendida como uma disciplina intrínseca à Ciência Histórica.
} 
com a vida prática, tanto surgindo de carências de orientação temporal quanto exercendo funções de orientação temporal. (RÜSEN, 2001).

Ao mesmo tempo, a Didática da História foi constituindo-se, desde o final dos anos 60, como disciplina científica "com questionamentos, métodos e objetos particulares". A ampliação da Ciência Histórica, possibilitou à Didática uma fundamentação da sua posição particular ao se ancordar na "(...) determinação da Historik (teoria da História) sobre a distinção e a conexão da Ciência da História e o mundo da vida humana". (RÜSEN; BERGMANN, 1978).

Foi neste processo de reformulação da Didática da História, a partir da sua relação com a Teoria da História, que se constituiu uma posição que a definia como uma sub-disciplina da Ciência Histórica. É esta posição que queremos analisar aqui.

\section{A Re-inclusão da Didática da História como sub-disciplina da Ciência da História}

O caráter disciplinar da Didática da História nunca foi consensual na Alemanha. Em 1978, Rüsen e Bergmann definiam duas posições extremas como determinantes deste debate. Por um lado, a Didática da História era vista como uma "sub-disciplina da Ciência da Histórica", por outro, era entendida como uma "sub-disciplina das Ciências da Educação". Segundo estes autores, entre as duas disciplinas existiam "uma escala de transições e posicionamentos", no qual localizava-se "a maioria das posições didáticas" da época. (RÜSEN; BERGMANN, 1978, p. 07).

Annette Kuhn (1977) mesmo entendeu a definição da Didática da História como uma sub-disciplina da Ciência Histórica como um passo atrás nas discussões didáticas. Para ela, a Didática da História era uma "ciência interdisciplinar que sustenta tanto elementos de uma Ciência da Educação crítico-comunicativa como também de uma Ciência da História crítica". (KUHN, 1980 , p. 65).

Entretanto, a partir do final dos anos 70, a compreensão de que a Didática da História era uma sub-disciplina da Ciência Histórica tornou-se a posição predominante. (SCHÖNEMANN, 2009). (SÜSSMUTH, 1980). 
Esta posição havia aparecido pela primeira vez em um grupo de trabalho do Historikertag (Encontro de historiadores organizado pela "Associação dos historiadores e das historiadoras da Alemanha" - Verband der Historiker und Historikerinnen Deutschlands) de Braunschweig em 1974. (KOSTHORT, 1977; KUHN, 1977).

Em 1976, tal posição ficou mais evidente quando o Historikertag de Mannheim concentrou-se na relação entre Teoria da História, Pesquisa Histórica e Didática da História. (SÜSSMUTH, 1980). A publicação do livro Geschichtswissenschaft: Didaktik - Forschung - Theorie, organizado por Kosthort (1977), pode ser entendida como um marco do aprofundamento desta posição ${ }^{6}$.

Quando a discussão sobre o caráter disciplinar da Didática da História é colocada em termos de confronto entre as disciplinas, de disputa pelo controle de uma área do saber nas Universidades, ela não conduz a um avanço. Rüsen e Bergmann, por exemplo, demonstravam a fraqueza da concepção daqueles que, ao entenderem a Didática da História como uma sub-disciplina da Ciência Histórica, tendiam "a ver todos os problemas didáticos gerais do ensino e da aprendizagem da História como resolvidos pela práxis da pesquisa histórica e da especificidade científica da escrita da História" (BERGMANN, 1978, p. 07). Da mesma forma, viam com desconfiança aquelas posições que tratavam a Didática da História como uma sub-disciplina da Educação e ignoravam a importância fundamental da Ciência Histórica nas questões relacionadas à orientação temporal dos homens na vida prática.

A relação da Didática da História com a Ciência Histórica deve, segundo os dois autores, "trazer critérios, que elas não particularizam", ao contrário,

(...) deve abrir para um abrangente e fértil trabalho didáticocientífico. Esses critérios devem servir para mediar a essencial dependência da Didática da História (como Didática da História) da Ciência da História, com sua relativa autoposição (como Didática da História) para a Ciência da História e com sua dependência da dos conhecimentos científicos da Educação (...). (BERGMANN, 1978, p. 08).

\footnotetext{
6 Este livro intitulado "Ciência da História: Didática - Pesquisa - Teoria" (Geschichtswissenschaft: Didaktik -Forschung - Theorie) está dividido em três contribuições. A primeira sobre Didática da História escrita por Karl Ernst-Jeismann. A segunda sobre a Pesquisa Histórica elaborada por Rudolf Vierhaus, e a última sobre Teoria da História, escrita por Jörn Rüsen. A organização do livro nestas três temáticas, Didática, Pesquisa e Teoria, reforçam a noção de que a Didática da História, a Pesquisa Histórica e a Teoria da História são três partes fundamentais da Ciência Histórica.
} 
Desta forma, as tarefas da Didática da História, determinadas a partir da relação intrínseca com a Ciência Histórica, "devem integralmente ser usadas para a validade e estimadas para as possibilidades de soluções que dela resultam igualmente para a Ciência da História, a Pedagogia e a Experiência de Ensino". (idem, ibidem).

É somente neste sentido, de uma aproximação da Didática da História com a Ciência Histórica para compreender as contribuições que ela fornece para as diferentes disciplinas, que entendemos o reconhecimento da Didática da História como uma sub-disciplina da Ciência Histórica.

Este reconhecimento implica, entretanto, em uma tomada de posição e em uma reformulação completa da Didática da História. Isto porque o termo subdisciplina, ou também disciplina-parte da Ciência Histórica apresenta uma superação da noção de que a Didática da História é uma disciplina da Ciência Pedagógica, como também da noção de que ela é uma ciência interdisciplinar autônoma.

Mas, os motivos desta reinclusão da Didática na Ciência Histórica na Ciência Histórica só podem ser compreendidos se também entendemos duas questões fundamentais. Primeiro, aquilo que Jeismann chamou de Função Didática Básica da História. Segundo, se definimos a Consciência Histórica (Geschichtsbewusstsein) como o objeto central da Didática da História.

Por Função Didática Básica da História (die didaktische Grundfunktion der Historie) "quer-se dizer que qualquer afirmação sobre o passado tem um elemento didático inerente". (JEISMANN, 1977). Desta forma, toda História, metodicamente regulada (científica) ou não, "nos diz alguma coisa", ou "significa alguma coisa para nós", no presente. Isto porque uma afirmação sobre o passado sempre conduz a "um processo de comunicação atual de compreensão sobre o passado" e se submete a uma "vontade de orientação presente".

Segue-se disto que os elementos didáticos compõem a própria produção do pensamento histórico. Não são, portanto, algo externo a ele. Édipo só arrancou os próprios olhos porque descobriu a sua história. Não o havia feito enquanto não sabia que a mulher que havia desposado era a sua própria mãe, e que o homem que havia assassinado, era o seu próprio pai. É isto o que constantemente a história provoca quando vemos que os nossos filhos são também nossos irmãos. Quem nos dera pudéssemos arrancar os nossos olhos e 
não ver o que fizemos ou o que fizeram conosco. Mas, como disse Nietzsche (2003), ponha-se a correr, apresse-se o passo, o passado corre com a gente, como corrente em nossos pés.

É por isto que, por mais que vários historiadores neguem qualquer utilidade para a História, é diante dela que decidimos arrancar o olho ou permanecermos cego. Édipo só poderia ser salvo de sua tragédia, se tivesse recusado a saber quem ele era ou se o mensageiro que lhe revelara a sua origem tivesse Ihe contado outra história.

Quando pensamos em Didática da História, é sobre este elemento de orientação temporal inerente a toda História que estamos pensando. Se Édipo era ou não filho de Laio, importa não só por mera curiosidade intelectual, mas porque isto pode destruir ou construir uma vida.

Neste sentido, a Didática da História não lida simplesmente com a educação ou com o ensino, mas com o modo como as representações sobre o passado produzem compreensões do presente e projeções de futuro. Isto é, a Didática da História lida com a orientação temporal inerentemente produzida pela História.

Entender a Didática da História a partir desta perspectiva da Função Didática Básica da História implica em uma reorientação completa do caráter disciplinar da Didática da História. Se a Didática da História lida com a orientação produzida pelas histórias, e a Ciência Histórica é uma forma específica de produção do pensamento histórico, a Didática da História é uma disciplina inerente à Ciência Histórica.

Como disciplina científica, a Didática da História tem como objeto este elemento didático de todas as histórias. Isto é, ela analisa a Consciência Histórica predominante em uma sociedade. (JEISMANN, 1977). Ou, para ser mais claro, ela investiga o modo como as interpretações do passado produzem orientações no presente e projeções de futuro.

A Didática da História lida então com a suma das operações mentais com as quais os homens reconstroem passados para se orientarem no presente. Ela não discute simplesmente a transmissão ou o ensino da História. Neste lidar com operações mentais de reconstrução de passado, seu objeto de pesquisa está diretamente relacionado ao trabalho da especialidade profissional do historiador. 
O que diferencia a Ciência Histórica de todas as outras formas de história é justamente o seu acréscimo de racionalidade, "que está presente na referência a um sistema teórico, no método histórico e no conhecimento histórico". (BERGMANN, 1989). Ou, como afirmava Rüsen (2007), a Ciência Histórica metodiza sua relação com as fontes (pertinência experiencial ou empírica), a sua relação com as ideias (pertinência interpretativa) e a sua relação com a narrativa (pertinência narrativa).

Ao produzir um acúmulo sistemático no processo de elaboração de afirmações sobre o passado humano, a Ciência Histórica torna-se a ciência competente para refletir sobre o modo como a Consciência Histórica é produzida.

Deixar com que este acúmulo científico sobre a produção do passado fique fechado nas Universidades e, mais especificamente, nas faculdades de História; enquanto os homens produzem e se relacionam, em suas vidas práticas, com diferentes pensamentos históricos, orientando suas vidas através deles; é um contrassenso.

No processo de especialização da Ciência Histórica, os historiadores, dedicados a cada uma das especialidades de sua ciência (seja a produção de narrativas históricas empíricas, seja a reflexão metateórica da História), não podem responder à necessidade de reflexão sobre a Consciência Histórica na vida prática. (BERGMANN, 1989; RÜSEN, 2007a).

Faz-se necessário, desta forma, uma disciplina específica, que esteja ancorada no acúmulo reflexivo da Ciência Histórica, para pensar a produção da Consciência Histórica na sociedade. Como sub-disciplina científica, ela aproveita todo o acúmulo sistemático da Ciência Histórica para sua investigação. Descuidar deste vínculo direto com a Ciência da História é, portanto, deixar com que o uso da História na vida pública e nas escolas ocorra sem o acúmulo sistemático alcançado por esta Ciência na especialização de pensar e produzir histórias.

Isto fica claro quando, na escola, a História ensinada se torna uma simplificação da produção historiográfica, ou mesmo ainda, uma representação que se contradiz com os avanços da historiografia. Também, no uso público da História, quando a Ciência da História se abstém de intervir com o seu método e seu avanço de reflexão sobre a produção de afirmações sobre o passado, ela permite que políticos e a grande mídia construam interpretações simplificadas 
sobre o passado, com o objetivo de orientar um tipo de ação política ou manter determinadas relações de dominação.

A Didática da História quando atua enquanto sub-disciplina da Ciência Histórica, investiga empiricamente todas as formas de produção do passado humano, nas escolas e na vida pública, levando o acréscimo de racionalização próprio da Ciência Histórica. Analisa, assim, as ideias históricas elaboradas, a forma como os documentos são interpretados, a estrutura narrativa destas histórias, sempre visando torná-las mais complexas e evitar o uso abusivo do passado humano.

A Didática da História se vincula, assim, à Teoria da História e à pesquisa histórica, com o objetivo de analisar as ideias, os métodos, as formas narrativas, com as quais os homens elaboram sua interpretação de passado, para orientarse temporalmente. É por isto que para Schönnemann (2009, p. 83), "a Didática da História, a pesquisa histórica e a Teoria da História formam partes independentes e interligadas de um todo maior - a Ciência Histórica.".

Definir a Didática da História como sub-disciplina da Ciência Histórica não significa, portanto, ignorar as contribuições das ciências afins. Ao contrário, o avanço destas ciências é fundamental para o desenvolvimento da Didática da História. Como afirma Jeismann:

O desenvolvimento das ciências do ensino é imprescindível para a concretização da Didática da História em área do ensino de História; a Psicologia tanto individual - como sobretudo como Psicologia Social - é uma das importantes ciências afins tanto para o dirigido processo de mediação como também para a compreensão da formação e transformação da Consciência Histórica (...); a Publicidade é imprescindível para uma Didática midiática (JEISMANN, 1977, p. 16).

Quando a Didática da História ignora seu vínculo com as ciências afins, ela é incapaz de cumprir os seus objetivos. Na análise da História escolar, por exemplo, se não leva em consideração os acúmulos alcançados pela Pedagogia e pela Psicologia da Aprendizagem, a análise didática tende a ignorar os saberes e interesses que envolvem a especificidade do ambiente escolar, bem como não é capaz de produzir um aprendizado complexo ao não compreender a relação entre os sujeitos da aprendizagem. Na análise dos usos da História pelos meios de comunicação de massa, se uma Didática da História ignora as teorias da 
comunicação, bem como as reflexões sobre as especificidades da linguagem midiática, ela atua ingenuamente, condenando sua análise ao esquematismo e sua intervenção a um voluntarismo acadêmico inócuo.

Porém, sem esta fundamentação sistemático-científica da Didática da História como sub-disciplina da Ciência Histórica, e, portanto, sem sua relação com a Teoria da História e com a Pesquisa da História, "a articulação com as ciências afins não fica clara e ainda torna-se possivelmente enganosa". (JEISMANN, 1977, p. 17). É, portanto, como sub-disciplina da Ciência da História, que ela deve se relacionar com as demais ciências. Como afirma Schönemann:

Especialmente integrada na Ciência da História, a Didática da História é, entretanto, bem consciente, quando ela mantém e se preocupa com o vínculo com suas ciências afins, especialmente a Pedagogia, a Psicologia e as Ciências Sociais sistemáticas (SCHÖNEMANN, 2009, p. 83).

A definição da Didática da História como sub-disciplina da História, desta forma, não pode se entregar de forma ingênua às disputas pelo controle das disciplinas existentes nas Universidades. Se pensarmos que a Ciência Histórica necessita de uma disciplina inerente que a pressione para que não se isole da vida prática dos homens; que o objeto de investigação da Didática da História não se reduz à metodologia do ensino de História nas escolas; que esta disciplina se abre para as contribuições das diferentes disciplinas afins, não podendo se realizar sem suas contribuições; e que da relação intrínseca entre Teoria da História e Didática da História, as Ciências da Educação podem auferir reflexões profundas sem perder suas especificidades; então, entenderemos que mais do que uma disputa pelas disciplinas existentes, o que está em jogo aqui é a constituição de uma nova disciplina. Uma disciplina sem a qual, os Otelos continuam matando as Desdêmonas, sem poder compreender que o velho lenço de linho perdido não era um indício de traição da esposa, mas de traição do amigo.

\section{Referências}


BERGMANN, K.; RÜSEN, J. Zum Verhältins von Geschichtswissenschaft und Geschichtsdidaktik. In BERGMANN \& RÜSEN (Hrsg.). Geschichtsdidaktik: Theorie für die Praxis. Düsseldorf: Pädagogischer Verlag Schwann, 1978.

BERGMANN, K. Geschichtsdidaktik als Sozialwissenschaft. In SÜSSMUTH, Hans. Geschichtsdidaktische Positionen: Bestands-aufnahme u. Neuorientierung. Pandeborn, München, Wien, Zürich: Schöningh, 1980.

. Geschichte in der didaktischen Reflexion. In Bergmann, Klaus.

Geschcihtsdidaktik: Beiträge zu einer Theorie historischen Lernens. Wochenschau Verlag, Schwalbach, 2008.

A História na Reflexão Didática. Revista Brasileira de História. São Paulo, v. 9, n. 19, pp. 29-42, set. 89/ fev. 90.

CARDOSO, O. Para uma definição de Didática da História. Revista Brasileira de História, São Paulo, v. 28, n. 55, June 2008. Disponível em: http://www.scielo.br/scielo.php?script=sci arttext\&pid=S010201882008000100008\&lng=en\&nrm=iso. Acesso em 06 de Abril 2010.

CERRI, L. F. Os Conceitos de Consciência Histórica e os desafios da Didática da História. Revista de História Regional. 6(2): 93-112, Inverno 2001.

- Didáticas da História no século XX: uma reflexão didática na história do Ensino de História no Brasil. Trabalho apresentado na Comunicação Coordenada homônima no IX Encontro Regional de História da ANPUH-PR. Ponta Grossa, junho de 2004. Disponível em:

http://www.pr.anpuh.org/resources/anpuhpr/anais/ixencontro/comunicacaocoordenada/Didaticas\%20da\%20historia\%20do\%20seculo\%20xx/LuisFCerri.htm . Acesso em 06 de abril de 2010.

. Didática da História: uma leitura teórica sobre a História na prática. Revista de História Regional 15(2): 264-278, Inverno, 2010.

. Fronteiras Interdisciplinares do Ensino de História. IV Seminário Perspectivas do Ensino de História, 2003, Ouro Preto. Anais do IV Seminário Perspectivas do Ensino de História, 2003. Disponível em: http://www.ichs.ufop.br/perspectivas/anais/GT1502.htm. Acesso em: 06 de abril de 2010.

JEISMANN, K. E. Didaktik der Geschichte: Die Wissenschaft von Zustand, Funktion und Veränderung geschichtlicher Vorstellung im Selbstverständnis der Gegenwart. In: KOSTHORST, Erich (Hrsg). Geschichtswissenschaft: Didaktik Forshung - Theorie. Göttingen: Vandenhoeck und Ruprecht, 1977.

. "Geschichtsbewusstsein" als zentrale Kategorie der Didaktik des Geschichtsunterrichts. In: JEISMANN, Karl-Ernst. Geschichte und Bildung: Beiträge zur Geschichtsdidaktik und zur Historischen Bildungsforschung. Panderborn; München. Wien; Zürich: Schöning, 2000.

KOSELLECK, R. Historia Magistra Vitae. In Futuro Passado: contribuição à semântica dos tempos históricos. Rio de Janeiro: Contraponto, 2006. 
KOSTHORST, E. (Hrsg). Geschichtswissenschaft: Didaktik - Forshung - Theorie. Göttingen: Vandenhoeck und Ruprecht, 1977.

KUHN, A. Einführung in die Didaktik der Geschichte. Zweite Auflage. Kösel-Verlag München., 1977.

. Geschichtsdidaktik in emanzipatorischer Absicht. Versuch einer kritischen Überprüfung. In: SÜSSMUTH, Hans. Geschichtsdidaktische Positionen. Paderborn, München, Zürich: Schöningh, 1980.

NIETZSCHE, F. Segunda consideração intempestiva: das vantagens e desvantagens da história para a vida. Rio de Janeiro: Relume Dumará, 2003.

RÜSEN, Jörn. Razão Histórica. Brasília: editora UnB, 2001.

. Reconstrução do Passado. Brasília: editora UnB, 2007.

. História Viva. Brasília: editora UnB, 2007a.

. Didática da História: passado, presente e perspectivas a partir do caso alemão. Práxis Educativa. Ponta Grossa, PR. v. 1, n. 2, p. 07-16, jul./dez. 2006.

SCHMIDT, M. A. História com Pedagogia: a contribuição da obra de Jonathas Serrano na construção do código disciplinar da História no Brasil. Revista Brasileira de História. São Paulo, ano/vol. 24, número 048. Associação Nacional de História, pp. 189-211, 2004.

. Concepções de Aprendizagem Histórica presentes em propostas curriculares brasileiras. História Revista, Goiânia, v. 14, n. 1, p. 203-213, jan./jun. 2009.

SCHÖNEMANN, B. Geschichtsdidaktik. In: MAYER, Ulrich; Pandel, Hans-Jürgen; SCHNEIDER, Gerhard \& SCHÖNEMANN, Bernd (Hrsg.). Wörterbuch Geschichtsdidaktik. Wochenschau Verlag, 2009.

SYWOTTEK, A. Geschichtswissenschaft in der Legitimationskrise: Ein Überblick über die Diskussion um Theorie und Didaktik der Geschichte in der Bundesrepublik Deutschland 1969-1973. Neue Gesellschaft, 1974.

SÜSSMUTH, H. Geschichtsdidaktische Positionen. Paderborn, München, Zürich: Schöningh, 1980.

URBAN, A. C. Didática da História: percursos de um código disciplinar no Brasil e na Espanha. 2009. Tese (Doutorado em Educação) - Setor de Educação, Universidade Federal do Paraná, Curitiba, 2009. 